\title{
Suitability of different tissue fixatives for subsequent PCR analysis of Cysticercus ovis
}

\author{
M. KOLESÁROVÁ, R. HERICH, M. LEVKUT jr., J. ČURLÍK, M. LEVKUT
}

University of Veterinary Medicine and Pharmacy in Košice, Slovakia

\begin{abstract}
Summary
PCR amplification of specific DNA regions is a powerful tool for retrospective studies, but not all preservation or fixation methods render DNA that is suitable for subsequent amplification. Several factors affect sensitivity of polymerase chain reaction (PCR) amplification. There were reported the effects of commonly used fixation solutions - $10 \%$ neutral buffered formalin, $20 \%$ neutral buffered formalin and Carnoy's solution and the efficiency of PCR amplification in fresh tissue and paraffin (or wax) embedded samples of Cysticercus ovis. DNA from samples was isolated and PCR product of $1300 \mathrm{bp}$ was amplified. Results indicated that the samples fixed in Carnoy's solution produced reliable amplification of desired fragments. The samples that were fixed in $10 \%$ and $20 \%$ neutral buffered formalin brought negative results.
\end{abstract}

Keywords: Cysticercus ovis; histology; formalin; Carnoy's solution; DNA

\section{Introduction}

Cysticercosis is a zoonosis caused by infection with larval Taenia spp., Taenia spp. are long, segmented, parasitic tapeworms (family Taeniidae, subclass Cestoda). These parasites have an indirect life cycle, cycling between a definitive and an intermediate host (Ogunremi et al., 2004). The larval form of any tapeworms (T. solium, T. saginata, T. crassiceps, T. ovis, T. taeniaeformis or T. hydatigena) is called as a cysticercus. Cysticerci are fluid-filled vesicles containing a single inverted protoscolex. Cysts are uniformly rounded or oval vesicles, varying in size from a few millimetres to $1-2 \mathrm{~cm}$ (in rare cases a growing cyst reaches several centimetres in diameter). This cyst is surrounded by a capsule of fibrous tissue. Cysticerci may be found almost anywhere, but each species has a predilection for certain tissues. For example, in pigs T. solium cysticerci are found mainly in the skeletal or cardiac muscles, liver, heart and brain. T. saginata in cattle and T. ovis in sheep are found mainly in the muscles (Lloyd, 1998).

Cysticerci do not usually stimulate an inflammatory response while they are alive, or after they have died and become calcified; however, while they are degenerating they can become inflamed. Cysticerci in various stages of viability can occur simultaneously in a host (Ogunremi et al., 2004).

Classical diagnosis of cysticercus spp. includes histological and histochemical methods for the detection of the developmental stages (Goldová et al., 2008, Turčeková et al., 2009). Diagnostic PCR is a molecular method used to amplify and thus optimize detection of specific nucleotide sequences. Recently, successful PCR amplification techniques have been performed on sections from routinely formalin-fixed, paraffin-embedded tissue for a number of important pathogenic microorganisms, including those of some species of Taenia spp. (Gonzalez et al., 2002).

Formalehyd as $4 \%$ aqueous solution is the most commonly used fixative in routine histopathology practice. It is inexpensive, readily available, stable, usable with almost any tissue and very importantly, it is a non-coagulative fixative. Formaldehyd acts by forming crosslinks between protein molecules, and soluble proteins are fixed to structural proteins. However, formaldehyd is not good fixative solution of nucleid acids. For the reaction to occur, it is necessary to destroy the hydrogen bond that holds together the two strands of DNA. This allows the reaction of formaldehyde with amino groups on the bases now exposed by the uncoiling of the double-stranded DNA molecule. Although this reaction causes damage to the main phosphodiester chain (McPherson et al., 1991).

Alternative fixatives that are currently used for molecular analysis is Carnoy's solution. Carnoy's solution is a fixative composed of $60 \%$ ethanol, $30 \%$ chloroform and $10 \%$ glacial acetic acid (Miething et al., 2006). Ethanol is a coagulating fixative that denatures the non-water-soluble 
proteins at room temperature and above. Ethanol can extract lipids, but does not have any effects on carbohydrates. The acetic acid in the fixative mixture is used to preserve chromosomes by coagulating nucleic acids. Acetic acid can break the cross-linkages between protein molecules and release lyophilic radicals that associate with water molecules. The chloroform in the fixative is to speed the slow tissue penetration rate of alcohol. The extreme hydrophobicity of chloroform results in rapid tissue dehydration and penetration. The nucleic acids of tissues fixed by Carnoy's were better preserved and easier to extract (Mitchell et al., 1985).

The development of PCR DNA amplification methods has afforded molecular studies of fixed paraffin-embedded tissue samples. Some fixation solutions can damage DNA, and thus deleteriously affect subsequent PCR analysis. The aim of this study was to examine the effect of commonly used fixation solutions (10\% neutral buffered formalin, $20 \%$ neutral buffered formalin and Carnoy's solution) on the efficiency of subsequent PCR amplification.

\section{Material and methods}

The cysts of Cysticercus ovis were collected between January and October 2010 from 20 sheep. All the sheep included in the experiment came from the Eastern Slovakia. The tissue samples with cysticerci obtained from the liver were fixed in $10 \%$ neutral buffered formalin, $20 \%$ neutral buffered formalin, Carnoy's solution -5 samples each and 5 samples were not treated with any fixative solutions. Two samples of each fixative treated tissue were embedded in paraffin.

\section{DNA isolation}

The DNA samples from fresh and fixed cysticerci were prepared as follows: the samples $20 \mathrm{mg}$ each were cut into small pieces and transferred to a microcentrifuge tube. A $180 \mu \mathrm{l}$ of lysis buffer and $400 \mu \mathrm{g}$ of Proteinase $\mathrm{K}$ (Qiagen, UK) were added and incubated overnight at $56^{\circ} \mathrm{C}$. After overnight incubation ethanol was added and the sample was centrifuged at $800 \mathrm{rpm}$ for $1 \mathrm{~min}$. The QIAamp DNA Mini Kit (Qiagen, UK) was used to extract the DNA from the tissue pellet in accordance with the tissue protocol. The DNA samples from paraffin-embedded specimens were prepared according to Greer et al. (1994): a paraffinblock was sliced into thin pieces and transferred to a microcentrifuge tube. A $200 \mu \mathrm{l}$ aliquot of xylene was added, mixed by inversion, heated for $15 \mathrm{~min}$ at $37^{\circ} \mathrm{C}$ and centrifuged at $12000 \mathrm{rpm}$ for $4 \mathrm{~min}$. The supernatant was removed and was added a fresh $200 \mu \mathrm{l}$ aliquot of xylene. The pellet was washed twice with $1 \mathrm{ml}$ of ethanol for 30 $\min$ at $37^{\circ} \mathrm{C}$ to remove residual xylene. The ethanol was removed by centrifugation for $10 \mathrm{~min}$ and the tissue pellet was air dried for DNA extraction using QIAamp DNA Mini Kit (Qiagen, UK).

PCR

The sequences of the primer pairs were prepared according to Mayta et al. (2000) for DNA amplification of Taenia spp. as follows: 5'GTCGTAACAAGGTTTCCGTA 3' and 5'ATATGCTTAAGTTCAGCGGGTAATC 3'.

PCR mixture contained $0.5 \mu \mathrm{M}$ of each primer, $0.2 \mathrm{mM}$ of each deoxynucleoside (dATP, dTTP, dCTP, dGTP) (Fermentas, Lithuania), $2.5 \mathrm{mM} \mathrm{MgCl}_{2}$ (Fermentas, Lithuania), 1x PCR buffer (Fermentas, Lithuania), 1.25 U Taq polymerase (Fermentas, Lithuania), and $\mathrm{H}_{2} \mathrm{O}$ to the total volume of $50 \mu \mathrm{l}$. The cycle for PCR consisted of 3 min at $94^{\circ} \mathrm{C}$ followed by 30 cycles consisting of $94^{\circ} \mathrm{C}$ for $30 \mathrm{~s}, 56^{\circ} \mathrm{C}$ for $30 \mathrm{~s}, 72^{\circ} \mathrm{C}$ for $10 \mathrm{~min}$ and final elongation at $72^{\circ} \mathrm{C}$ for $10 \mathrm{~min}$ with a Techne PTC thermocycler (Techne, UK). The PCR products (15 $\mu$ l of each) were separated by electrophoresis on a $1 \%$ agarose gel buffered with 1X TAE buffer (Merck, Germany) containing GelRed Nucleic Acid Gel Stain, (Biotium, UK) at $90 \mathrm{~V}$ for $50 \mathrm{~min}$.

\section{Results and discussion}

PCR amplification with specific primers resulted in the detection of a single band of approximately $1300 \mathrm{bp}$ for $C$. ovis. The PCR amplified product of $1300 \mathrm{bp}$ was present in the samples that were fixed in Carnoy's solution (no. 6,9 of lines) and fresh sample of C. ovis (no. 2,3 of lines). In the samples that were fixed in $10 \%$ and $20 \%$ neutral buffered formalin a PCR amplified product was not detected. The PCR products of each sample are illustrated in Fig. 1.

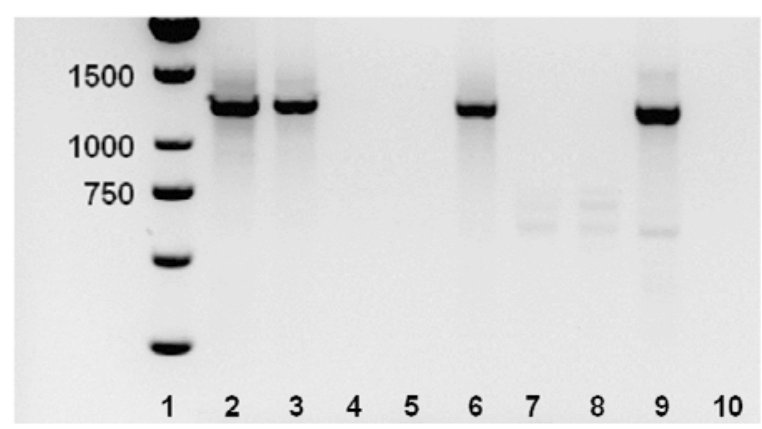

Fig. 1. The PCR products of each sample.

lane 1-1kb DNA ladder (Fermentas, Lithuania), lane 2,3 - unfixed samples of $C$. ovis, lane $4-C$. ovis fixed in $10 \%$ neutral buffered formalin, lane 5 - C.ovis fixed in $20 \%$ neutral buffered formalin, lane $6-$ C. ovis fixed in Carnoy's solution, lane $7-$ C.ovis fixed in $10 \%$ neutral buffered formalin with paraffin-embedded sample, lane $8-C$. ovis fixed in $20 \%$ neutral buffered formalin with paraffin-embedded sample, lane $9-C$. ovis fixed in Carnoy's solution with paraffin-embedded sample and lane 10 - negative

Diagnosis of zoonoses such as cysticercosis, is performed based on the clinical manifestations, imaging examination, serology, and histopathology. Although the histopathology provides highly definitive evidences for diagnosis of cysticercosis, it is occasionally difficult to specify causative parasites due to the degeneration or calcification of the lesions (Yamasaki et al., 2007). The success of any PCR-based study of fixed, paraffin-embedded material depends on several factors, including the fixative used in the tissue processing, the duration of the fixation, the age of the paraffin block and the length of DNA fragment to be amplified. 
Previous studies of Foss et al. (1994) were focused on the effects of fixatives on the tissues fixed in neutral buffered formalin and Carnoy's and reported that high-molecular weight DNA was extracted from Carnoy's fixed tissues. In our study, we found that Carnoy's fixed tissues yielded better PCR products in either event and detected $1300 \mathrm{bp}$ fragments. The study of Miething et al. (2006) showed the influence of fixative solutions on DNA as well as on the histological structures and their significance with regard to further DNA manipulation. The most suitable substances for fixation with possible subsequent DNA analysis were Carnoy's solution, glutaraldehyde and formalin. By using of Carnoy's solution and glutaraldehyde it was possible to amplify and detect PCR product with up to $800 \mathrm{bp}$ fragments. In the formalin-fixed tissues the PCR product was detected only up to the length of $150 \mathrm{bp}$ to $170 \mathrm{bp}$ fragments. Such similar results were found in regard to the duration of fixation and the detection of DNA as reported, for example, by Greer et al. (1994) and Wiegand et al. (1996). In contrast with this study our results showed that in formalin-fixed tissues the PCR amplified product was not detected. Ke et al., (2001) found that aldehyde-based fixatives, like neutral buffered formalin, can damage DNA in its form and structure. Our results confirm that neutral buffered formalin - in different concentrations - damaged DNA and ihibited the effect of subsequent PCR analysis.

Our result are in agreement with the recent studies of Takagi et al. (2004) and Miething et al. (2006), which confirm that Carnoy's and glutaraldehyde are more suitable for tissue fixation than neutral buffered formalin in different concentrations that produces variable results. Carnoy's solution is suggested to be an alternative for preserving the tissues that are subsequently used for DNA sequencing. Eventually, Mitchell et al. (1985) stated that Carnoy's treated tissues had a better performance in immunohistochemical localization of tissue antigens than those treated by formalin, because the immunoreactivity of some antigens was reduced by formaldehyde and generated false negative results.

In addition, DNA extraction and PCR amplification are fundamental to most DNA assays, and the accessibility and accuracy of the DNA is important for further analyses. Fixatives, used for preserving archived tissues, can be used not only for maintaining the tissue structures, but also for protection of DNA from damage.

\section{Conclusions}

According to our results we can contribute to better fixative abilities of Carnoy's solution for DNA preservation in samples when compared to formalin. Carnoy's solution is less used in histological practice, but it has clear advantages for subsequent DNA applications.

\section{Acknowledgement}

This work was supported by the Slovak Research and Development Agency under the contract No. LPP-0219-09.

\section{References}

Foss, R. D., Guha-Thakurta, N., CAnRan, R. M., GUTMAN, P. (1994): Effects of fixative and fixation time on the extraction and polymerase chain reaction amplification of RNA from paraffin-embedded tissue: Comparison of two housekeeping gene mRNA controls. Diagn. Mol. Pathol., 51: 148 - 155

GoldovÁ, M., Tóth, Š., LetKovÁ, V., MoJŽIŠOVÁ, J., KožÁrovÁ, I., Pomfy, M. (2008): Comparison of the histological methods in the diagnostic of deer cysticercosis. Helminthologia, 3: 121 - 125. DOI: 10.2478/s11687008-0023-2

Gonzalez, L. M., Montero, E., Puente, S., LopezVelez, R., Hernandez, M., Sciutto, E., Harrison, L. J. S., Parkhouse, R. M. E., GARAte, T. (2002): PCR tools for the differential diagnosis of Taenia saginata and Taenia solium taeniasis/cysticercosis from different geographical regions. Diagn. Microbiol. Infect. Dis., 1: 243 249. DOI: 10.1016/S0732-8893(01)00356-X

Greer, C. E., Wheeler, C. M., Manos, M. M. (1994): Sample preparation and PCR amplification from paraffinembedded tissues. Genome Res., 10: 113 - 122

KE, W. Z., YU, D. W., GU, B. P., ZhuAnG, Z. W. (2001): Raman spectroscopic study of microscopic damage on the space structure of DNA with acetic acid. Biochemistry, 21: $790-793$

LlOYD, S. (1998): Cysticercosis and taeniosis Taenia saginata, Taenia solium and Asian Taenia. In: Zoonoses. Biology, Clinical Practice, and Public Health Control. Oxford University Press, Oxford, UK, 635 - 649

Mayta, H., Talley, A., Gilman, R. H., Jimenez, J., Verastegui, M., Ruiz, M., Garcia, H. H., Gonzalez, E. (2000): Differentiating Taenia solium and Taenia saginata infections by simple hematoxylin-eosin staining and PCRrestriction enzyme analysis. J. Clin. Microbiol., 1: 133 - 137 McPherson, M. J., Graham, R., TAYlor, P. Q. (1991): PCR: a practical approach. Oxford University Press Inc., New York, 33 - 37

Miething, F., Hering, S., Hanschke, B., Dressler, J. (2006): Effect of fixation to the degradation of nuclear and mitochondrial DNA in different tissues. J. Histochem. Cytochem., 3: 371 - 374. DOI: 10.1369/jhc.5B6726.2005

Mitchell, D., Ibrahim, S., Gusterson, B. A. (1985): Improved immunohistochemical localization of tissue antigens using modified methacarn fixation. J. Histochem. Cytochem., 2: 491 - 495

OGunRemi, O., MacDonald, G., GeERTs, S., BRAndt, J. (2004): Diagnosis of Taenia saginata cysticercosis by immunohistochemical test on formalin-fixed and paraffinembedded bovine lesions. J. Vet. Diagn. Invest., 22: 438 441. DOI: $10.1177 / 104063870401600513$

Takagi, H., Shibutani, M., Kato, N., Fujita, H., Lee, K.Y., TAKigami, S., Mitsumori, K., Hirose, M. (2004): Microdissected region-specific gene expression analysis with methacarn-fixed, paraffin-embedded tissues by RTPCR. J. Histochem. Cytochem., 4: 903 - 913. DOI: 10.1369/jhc.3A6215.2004 
TURČEKOVÁ, L., ŠNÁBel, V., DUdiŇÁK, V., GaŠPar, V., DUBINSKÝ, P.: Prevalence of cystic echinoccocosis in pig from Slovakia, with evaluation of size, fertility and number of hydatid cysts. Helminthologia, 2009, 46 (3): 151 - 158. DOI: 10.2478/s11687-009-0029-4

Wiegand, P., DOMHO, Ver J., BrinKManN, B. (1996):
DNA-Degradation in formalinfixiertem Gewebe. Pathologe, 8: $451-454$

Yamasaki, H., NaKaya, K., NAKaO, M., SaKo,Y., Ito A. (2007): Mitochondrial DNA diagnosis for cestode zoonoses: application to formalin-fixed paraffin-embedded tissue specimens. Southeast Asian J. Trop. Med. Public Health, 38 (Suppl 1): 166 - 174

ACCEPTED JANUARY 30, 2012 